\title{
THE EXAMINATION OF EFFECTS ON PERCEPTIONS OF INNOVATION CHARACTERISTICS AND PURCHASE INTENTION OF ELECTRONIC BOOKS
}

\author{
Hsiu-LiLiao, Chung Yuan University, hsiuliliao@cycu.edu.tw \\ Chen-Huei Chou, College of Charleston, ChouC@cofc.edu \\ Bo-Hsiu Chen, Chung Yuan University,fly770602@hotmail.com
}

\begin{abstract}
E-books have changed the way to publish and the way to read. The books are stored digitally and can be loaded by various readers. In this study, we examine the effect of gender and format of e-books toward the perceptions of innovation characteristics and purchase intention of the books. Following a $2 x 2$ experimental design on the content (static versus dynamic) and reader (computer versus tablet), we randomly assign 200 volunteers into four groups. After 10 minutes reading the assigned content on the assigned reader, the participants are asked to rate the relative advantage, compatibility, complexity, trialability, observability, flow, and purchase intention based on their reading experience. Male showed stronger perceptions of innovation characteristics and purchase intention of e-books. Compared with computer e-book readers, tablet readers generated higher perceptions of innovation characteristics and purchase intention of e-books. Surprisingly, there was no difference between the readers reading static or dynamic contents.
\end{abstract}

Keywords: E-book, perception of innovation characteristics, purchase intention, gender

\section{INTRODUCTION}

Electronic books (e-books) are the books stored in a digital format which can be accessible by readers through various devices such as personal computer, laptop, personal digital assistant (PDA), smart phone, e-book reader, tablet, etc. Since the release of a breakthrough product-kindle — by Amazon in 2007, this e-book reader changed the way to deploy e-books. Apple Inc. introduced its tablet-iPad - in 2010, this multi-purpose computing device further dominated the market of hand-held devices. Because of its multimedia functionality, it has also made the reading interactive and interesting. Finally, the e-books have been evolved from black-and-white static information to colorful interactive contents. Even though the books are no longer mainly sold in physical bookstores, they are deployed through online virtual stores in the cloud.

The e-book industry is currently facing the innovation of technologies. Based on the diffusion of innovations theory [6], an individual's decision to adopt or reject an innovation may be influenced by intrinsic characteristics of innovations such as relative advantage, compatibility, complexity, triability, and observability. Relative advantage refers to the advance of an innovation over the past generation. The level of compatibility measures the fit between an innovation and individual's life. If the perceived difficulty of an innovation is high, the chance of the individual's adoption is low. An individual may be more likely to adopt an innovation if there is a chance to try the innovation. The observability measures the visibility of an innovation. A visible innovation would enhance the communication among individuals.

Moreover, Csıkszentmihályi [3] defined that flow is "a state of concentration or complete absorption with the activity at hand and the situation. It is a state in which people are so involved in an activity that nothing else seems to matter." Based on the flow theory, Csıkszentmihályi [2], Lu et al. [5] found that once individuals are in the state of flow, the intention of the behavior is strengthened.

Due to the innovation of e-books, recent studies examined the factors of the intention to adopt e-books. For example, Jung et al. [7] found that younger adults showed stronger intention to the use of e-books. Also, individuals' intention to use e-books was influenced by personal innovativeness and perceived attributes of e-book readers. Shin [8] applied Uses and Gratifications Theory, Expectation Confirmation Theory, and Diffusion Theory to examine the affective factors to the use of e-books. Confirmation, gratification, and demographics were found to be significant. Due to the electronic nature of the e-books, they are capable of delivering contents in a variety of formats. To boost the sales, e-book publishers tend to include fancy animations in the books to attract potential buyers. In addition, personalization and customization based on readers' profile can be easily done through the electronic distribution. 
While many factors have been found affecting the intention to use e-books in the literature, little attention has been paid on the content format of the e-books and users' profile such as gender. This study attempts to fill in this gap by answering the following research questions:

- Does gender have any impact on the perceptions of innovation characteristics and purchase intention of ebooks?

- Does the format of the e-book (static versus dynamic) have any impact on the perceptions of innovation characteristics and purchase intention of e-books?

The rest of the paper is organized as follows. We first discuss the research methodology for the experiments conducted in this study. Next we provide the results for the analyses. Finally, conclusion is made and future directions are suggested.

\section{RESEARCH METHODOLOGY}

\section{Research Design}

In order to answer our research questions, we recruited volunteers to participate our experiment. We prepared two formats of e-books: one has textual information with static pictures and another includes textual information with animations. The e-book reader used in the experiment was a computer or a tablet. Based on the two (static versus dynamic format) by two (computer versus tablet reader) experimental design, we randomly assigned the participants into one of the four groups. Each of the participants spent 10 minutes on the given e-book format with the assigned reader. After their reading, we distributed a survey to them. The questionnaire contained items about participants' demographic information as well as 36 items related to perceptions of innovation characteristics and purchase intention. These 36 items covered seven measure including relative advantage, compatibility, complexity, trialability, observability, flow, and purchase intention of e-books. The items from each measure were adapted from the literature. There were four to six items in a measure. Every item was evaluated using a 7-point Likert scale where $1=$ strongly disagree and $7=$ strongly agree.

\section{Participants}

We recruited 200 volunteers to participate the experiment. Each of them was randomly assigned to one of the four groups represented by (e-book reader, content format): (computer, dynamic), (computer, static), (tablet, dynamic), (tablet, dynamic). Each group included 50 participants. 200 copies of questionnaires were distributed at the end of the experiment and 200 copies of complete valid responses were collected. 116 of the participants were male (58\%) and 84 of them were female $(42 \%)$.

\section{ANALYSIS AND RESULTS}

\section{Measures}

Other than demographic information about participants, several measures were included in the questionnaire. The measures included relative advantage, compatibility, complexity, trialability, observability, flow, and purchase intention. Reliability is a reliable measurement to access the consistency of items [1][9]. In order to access the reliability of the measures, we relied on Cronbach's $\alpha$. It is suggested that all items' Cronbach's $\alpha$ are above 0.7 [4]. The item average, standard deviation, and measure's Cronbach's $\alpha$ are listed in Table 1. Based on our results, the threshold was made by all items since the Cronbach's $\alpha$ values were all above 0.7 . With a Cronbach's $\alpha$ value above 0.7 , internal consistency of survey items in a construct can be assured. It demonstrates the consistent examination of a construct using multiple survey questions. 


\section{Issues in Information Systems}

Volume 15, Issue II, pp. 1-7, 2014

Table 1. Item average, standard deviation, and reliability

\begin{tabular}{|c|c|c|c|c|}
\hline Measure & Item & Average & $\begin{array}{l}\text { Standard } \\
\text { Deviation }\end{array}$ & Cronbach's $\alpha$ \\
\hline \multirow{6}{*}{ Relative advantage } & RA 1 & 4.97 & 1.452 & \multirow{6}{*}{.768} \\
\hline & RA_2 & 5.50 & 1.345 & \\
\hline & RA_3 & 6.09 & 1.057 & \\
\hline & $\mathrm{RA} 4$ & 5.43 & 1.250 & \\
\hline & RA_5 & 4.16 & 1.382 & \\
\hline & RA 6 & 4.94 & 1.355 & \\
\hline \multirow{5}{*}{ Compatibility } & $\mathrm{CO}_{-} 1$ & 6.07 & 1.455 & \multirow{5}{*}{.745} \\
\hline & $\mathrm{CO}_{2} 2$ & 6.40 & .961 & \\
\hline & $\mathrm{CO} 3$ & 4.17 & 1.540 & \\
\hline & $\mathrm{CO}_{-} 4$ & 5.24 & 1.324 & \\
\hline & CO_5 & 4.37 & 1.501 & \\
\hline \multirow{4}{*}{ Complexity } & COM_1 & 4.14 & 1.674 & \multirow{4}{*}{.807} \\
\hline & COM_2 & 4.85 & 1.386 & \\
\hline & COM_3 & 4.97 & 1.454 & \\
\hline & COM 4 & 5.38 & 1.163 & \\
\hline \multirow{4}{*}{ Trialability } & TR_1 & 5.66 & 1.187 & \multirow{4}{*}{.857} \\
\hline & TR_2 & 5.72 & 1.126 & \\
\hline & TR_3 & 5.47 & 1.493 & \\
\hline & TR_4 & 5.52 & 1.240 & \\
\hline \multirow{5}{*}{ Observability } & $\mathrm{OB} 1$ & 4.65 & 1.310 & \multirow{5}{*}{.851} \\
\hline & $\mathrm{OB} 2$ & 4.06 & 1.595 & \\
\hline & $\mathrm{OB} 3$ & 4.73 & 1.317 & \\
\hline & $\mathrm{OB} 4$ & 4.16 & 1.536 & \\
\hline & OB 5 & 4.85 & 1.242 & \\
\hline \multirow{6}{*}{ Flow } & FL_1 & 4.32 & 1.360 & \multirow{6}{*}{.905} \\
\hline & FL_2 & 4.38 & 1.365 & \\
\hline & FL_3 & 4.11 & 1.471 & \\
\hline & FL_4 & 4.00 & 1.530 & \\
\hline & FL_5 & 3.51 & 1.490 & \\
\hline & FL_6 & 4.13 & 1.503 & \\
\hline \multirow{6}{*}{ Purchase intention } & PI_1 & 4.16 & 1.504 & \multirow{6}{*}{.914} \\
\hline & PI_2 & 4.18 & 1.510 & \\
\hline & PI_3 & 5.10 & 1.395 & \\
\hline & PI_4 & 4.78 & 1.368 & \\
\hline & PI_5 & 4.21 & 1.465 & \\
\hline & PI_6 & 3.78 & 1.611 & \\
\hline
\end{tabular}

\section{Factor Analysis}

This study aims to examine the influence of gender, format of e-books, and e-book reader on the perceptions of innovation characteristics and purchase intention. Based on the 2 by 2 experimental design, we used two-way ANOVA analyses to examine the group difference. We had one dedicated ANOVA analysis for each measure. The average of the measure items was used to represent the rating of the measure. Table 2 summarizes the basic statistics of the experiments toward various characteristics. The 200 participants were randomly assigned into four experimental groups according to the assigned reader and content format. 50 participants were arranged for each group. In the group using computer reader for dynamic content, 29 were male and 21 were female. 20 male and 30 female participants were put to use computer reader for static content. In addition, 33 male and 17 female participants used tablet reader for dynamic content. In the setting using tablet reader for static content, 34 male and 16 female participants were assigned. According to the summary statistics in Table 2, the mean of a measure differs 


\section{Issues in Information Systems \\ Volume 15, Issue II, pp. 1-7, 2014}

in different settings. We used ANOVA to test the significant difference among the means. The results and discussions are reported as follows.

Table 2. Summary statistics of ANOVA analysis

\begin{tabular}{|c|c|c|c|c|c|}
\hline Measure & Gender & $\begin{array}{c}\text { Format } \\
\text { (reader, content format) }\end{array}$ & Mean & Standard Deviation & Size \\
\hline \multirow{8}{*}{ Relative Advantage } & \multirow{4}{*}{ Male } & Computer, Dynamic & 4.94 & 0.88 & 29 \\
\hline & & Computer, Static & 5.08 & 0.92 & 20 \\
\hline & & Tablet, Dynamic & 5.61 & 0.97 & 33 \\
\hline & & Tablet, Static & 5.55 & 0.79 & 34 \\
\hline & \multirow{4}{*}{ Female } & Computer, Dynamic & 4.65 & 0.89 & 21 \\
\hline & & Computer, Static & 4.94 & 0.78 & 30 \\
\hline & & Tablet, Dynamic & 5.29 & 0.72 & 17 \\
\hline & & Tablet, Static & 5.11 & 0.74 & 16 \\
\hline \multirow{8}{*}{ Compatibility } & \multirow{4}{*}{ Male } & Computer, Dynamic & 4.67 & 1.34 & 29 \\
\hline & & Computer, Static & 5.11 & 0.88 & 20 \\
\hline & & Tablet, Dynamic & 5.27 & 1.18 & 33 \\
\hline & & Tablet, Static & 5.52 & 0.83 & 34 \\
\hline & \multirow{4}{*}{ Female } & Computer, Dynamic & 4.44 & 0.88 & 21 \\
\hline & & Computer, Static & 4.61 & 1.04 & 30 \\
\hline & & Tablet, Dynamic & 5.00 & 0.95 & 17 \\
\hline & & Tablet, Static & 4.83 & 1.22 & 16 \\
\hline \multirow{8}{*}{ Complexity } & \multirow{4}{*}{ Male } & Computer, Dynamic & 4.22 & 1.36 & 29 \\
\hline & & Computer, Static & 5.04 & 1.10 & 20 \\
\hline & & Tablet, Dynamic & 5.16 & 1.14 & 33 \\
\hline & & Tablet, Static & 5.39 & 1.11 & 34 \\
\hline & \multirow{4}{*}{ Female } & Computer, Dynamic & 4.21 & 0.92 & 21 \\
\hline & & Computer, Static & 4.52 & 0.85 & 30 \\
\hline & & Tablet, Dynamic & 4.88 & 0.99 & 17 \\
\hline & & Tablet, Static & 5.19 & 0.75 & 16 \\
\hline \multirow{8}{*}{ Trialability } & \multirow{4}{*}{ Male } & Computer, Dynamic & 5.21 & 1.31 & 29 \\
\hline & & Computer, Static & 5.60 & 0.87 & 20 \\
\hline & & Tablet, Dynamic & 5.96 & 1.03 & 33 \\
\hline & & Tablet, Static & 6.05 & 0.81 & 34 \\
\hline & \multirow{4}{*}{ Female } & Computer, Dynamic & 5.12 & 1.02 & 21 \\
\hline & & Computer, Static & 5.48 & 0.93 & 30 \\
\hline & & Tablet, Dynamic & 5.59 & 1.01 & 17 \\
\hline & & Tablet, Static & 5.42 & 1.22 & 16 \\
\hline \multirow{8}{*}{ Observability } & \multirow{4}{*}{ Male } & Computer, Dynamic & 3.88 & 1.17 & 29 \\
\hline & & Computer, Static & 4.76 & 1.12 & 20 \\
\hline & & Tablet, Dynamic & 4.78 & 1.10 & 33 \\
\hline & & Tablet, Static & 5.11 & 1.14 & 34 \\
\hline & \multirow{4}{*}{ Female } & Computer, Dynamic & 4.07 & 0.95 & 21 \\
\hline & & Computer, Static & 4.11 & 0.87 & 30 \\
\hline & & Tablet, Dynamic & 4.58 & 0.91 & 17 \\
\hline & & Tablet, Static & 4.55 & 0.97 & 16 \\
\hline \multirow{7}{*}{ Flow } & \multirow{4}{*}{ Male } & Computer, Dynamic & 3.13 & 1.32 & 29 \\
\hline & & Computer, Static & 4.03 & 1.38 & 20 \\
\hline & & Tablet, Dynamic & 4.68 & 0.92 & 33 \\
\hline & & Tablet, Static & 4.66 & 0.99 & 34 \\
\hline & \multirow{3}{*}{ Female } & Computer, Dynamic & 3.25 & 1.03 & 21 \\
\hline & & Computer, Static & 3.84 & 0.99 & 30 \\
\hline & & Tablet, Dynamic & 4.53 & 0.99 & 17 \\
\hline
\end{tabular}


Issues in Information Systems

Volume 15, Issue II, pp. 1-7, 2014

\begin{tabular}{|c|c|c|c|c|c|}
\hline & & Tablet, Static & 4.42 & 0.62 & 16 \\
\hline \multirow{8}{*}{ Purchase Intention } & \multirow{4}{*}{ Male } & Computer, Dynamic & 3.68 & 1.49 & 29 \\
\hline & & Computer, Static & 4.55 & 0.95 & 20 \\
\hline & & Tablet, Dynamic & 4.68 & 1.14 & 33 \\
\hline & & Tablet, Static & 4.94 & 1.20 & 34 \\
\hline & \multirow{4}{*}{ Female } & Computer, Dynamic & 3.72 & 1.17 & 21 \\
\hline & & Computer, Static & 3.96 & 1.15 & 30 \\
\hline & & Tablet, Dynamic & 4.80 & 0.68 & 17 \\
\hline & & Tablet, Static & 4.67 & 1.00 & 16 \\
\hline
\end{tabular}

Table 3 shows the results of ANOVA significance test for all measures. Gender difference was found in evaluating relative advantage, compatibility, trialability, and observability. Male's ratings on these measures were significantly greater than female's ratings. Consistently, e-book formats made significant differences on the ratings of all measures.

Table 3. Results of two, way ANOVA factor analysis

\begin{tabular}{|l|l|c|c|}
\hline \multicolumn{1}{|c|}{ Measure } & \multicolumn{1}{|c|}{ Factor } & F & p-value \\
\hline \multirow{3}{*}{ Relative Advantage } & Gender & 5.577 & $.019^{* *}$ \\
\cline { 2 - 4 } & Format & 5.897 & $.001^{* *}$ \\
\cline { 2 - 4 } & Gender x Format & .248 & .863 \\
\hline \multirow{3}{*}{ Complexity } & Gender & 7.310 & $.007^{* * *}$ \\
\cline { 2 - 4 } & Format & 3.375 & $.020^{* *}$ \\
\cline { 2 - 4 } & Gender x Format & .462 & .709 \\
\hline \multirow{3}{*}{ Trialability } & Gender & 2.576 & .110 \\
\cline { 2 - 4 } & Format & 8.468 & $.000^{* * *}$ \\
\cline { 2 - 4 } & Gender x Format & .471 & .703 \\
\hline \multirow{3}{*}{ Fbservability } & Gender & 4.039 & $.046^{* *}$ \\
\cline { 2 - 4 } & Format & 3.496 & $.017^{* *}$ \\
\cline { 2 - 4 } & Gender x Format & .680 & .565 \\
\hline \multirow{3}{*}{ Purchase Intention } & Gender & 3.899 & $.050^{* *}$ \\
\cline { 2 - 4 } & Format & 5.914 & $.001^{* * *}$ \\
\cline { 2 - 4 } & Gender x Format & 1.554 & .202 \\
\hline \multirow{2}{*}{$\mathrm{P}<0.1 ;{ }^{* *} \mathrm{P}<0.05 ;{ }^{* * *} \mathrm{P}<0.01$} & .545 & .461 \\
\cline { 2 - 4 } & Gender & 17.965 & $.000^{* * *}$ \\
\cline { 2 - 4 } & Format & .279 & .840 \\
\cline { 2 - 4 } & Gender x Format & .31036 & .310 \\
\cline { 2 - 4 } & Gender & .930 & .427 \\
\hline
\end{tabular}

In order to identify the significantly different format(s), we conducted post hoc Bonferroni pair-wise comparisons among the four groups of formats: (computer, dynamic), (computer, static), (tablet, dynamic), and (tablet, static). The results of Bonferroni tests are listed in Table 4. Also, there was no interaction affect between gender and e-book formats in any of measures. 


\section{Issues in Information Systems}

Volume 15, Issue II, pp. 1-7, 2014

Table 4. P-values of post hoc pair, wise comparisons

\begin{tabular}{|c|c|c|c|c|c|}
\hline \multirow{2}{*}{ Measure } & \multirow{2}{*}{$1^{\text {st }}$ Format } & \multicolumn{4}{|c|}{$2^{\text {nd }}$ format } \\
\hline & & Computer, Dynamic & Computer, Static & Tablet, Dynamic & Tablet, Static \\
\hline \multirow{4}{*}{$\begin{array}{l}\text { Relative } \\
\text { Advantage }\end{array}$} & Computer, Dynamic & --- & 1.000 & $0.000^{* * * *}$ & $0.003^{* * *}$ \\
\hline & Computer, Static & --- & --- & $0.018^{* *}$ & 0.085 \\
\hline & Tablet, Dynamic & --- & --- & --- & 1.000 \\
\hline & Tablet, Static & --- & --- & --- & --- \\
\hline \multirow{4}{*}{ Compatibility } & Computer, Dynamic & --- & 1.000 & $0.031^{* *}$ & $0.005^{* * * *}$ \\
\hline & Computer, Static & --- & --- & 0.521 & 0.140 \\
\hline & Tablet, Dynamic & --- & --- & --- & 1.000 \\
\hline & Tablet, Static & --- & --- & --- & --- \\
\hline \multirow{4}{*}{ Complexity } & Computer, Dynamic & --- & 0.115 & $0.001^{* * *}$ & $0.000^{* * *}$ \\
\hline & Computer, Static & --- & --- & 0.680 & $0.033^{* *}$ \\
\hline & Tablet, Dynamic & --- & --- & --- & 1.000 \\
\hline & Tablet, Static & --- & --- & --- & --- \\
\hline \multirow{4}{*}{ Trialability } & Computer, Dynamic & --- & 0.515 & $0.009^{* * *}$ & $0.007^{* * *}$ \\
\hline & Computer, Static & --- & --- & 0.800 & 0.694 \\
\hline & Tablet, Dynamic & --- & --- & --- & 1.000 \\
\hline & Tablet, Static & --- & --- & --- & --- \\
\hline \multirow{4}{*}{ Observability } & Computer, Dynamic & $-\cdots$ & 0.305 & $0.003^{* * *}$ & $0.000^{* * *}$ \\
\hline & Computer, Static & --- & --- & 0.663 & $0.052^{*}$ \\
\hline & Tablet, Dynamic & --- & --- & --- & 1.000 \\
\hline & Tablet, Static & --- & --- & --- & --- \\
\hline \multirow{4}{*}{ Flow } & Computer, Dynamic & --- & $0.004^{* * *}$ & $0.000^{* * *}$ & $0.000^{* * *}$ \\
\hline & Computer, Static & ---- & --- & $0.006^{* * *}$ & $0.012^{* *}$ \\
\hline & Tablet, Dynamic & --- & --- & --- & 1.000 \\
\hline & Tablet, Static & --- & --- & --- & --- \\
\hline \multirow{4}{*}{$\begin{array}{l}\text { Purchase } \\
\text { Intention }\end{array}$} & Computer, Dynamic & --- & 0.198 & $0.000^{* * *}$ & $0.000^{* * *}$ \\
\hline & Computer, Static & --- & --- & 0.149 & $0.031^{* *}$ \\
\hline & Tablet, Dynamic & --- & --- & --- & 1.000 \\
\hline & Tablet, Static & --- & --- & --- & --- \\
\hline
\end{tabular}

$* \mathrm{P}<0.1 ; * * \mathrm{P}<0.05 ; * * * \mathrm{P}<0.01$

Interestingly, the format of the e-books (static versus dynamics) made no significant difference to the evaluations of all the measures. However, when loading contents with dynamic animations, there was a consistent significant difference between the reading platforms (computer versus tablet) over the ratings of all measures. The participants' agreements toward the measures were stronger when reading the e-book contents on tablet. In general, the reading experience was more pleasant on a tablet than a computer. In all cases, the ratings of the measures when reading static contents on a tablet were higher than reading dynamic contents on a computer.

\section{CONCLUSIONS}

In this study, we found that gender made a significant difference on the perceptions of innovation characteristics. Specifically, male demonstrated significant stronger agreements of relative advantage, compatibility, complexity, trialability, observability, and flow toward the use of e-books than female. Male also showed significant stronger purchase intention of e-books. Regarding the reading platforms, tablets generated higher user perceptions of innovation characteristics and purchase intention of e-books than computers. No matter which reading platform was used, the format of the e-books (static versus dynamics) made no significant difference.

The results of the analyses in this study rely on the volunteers who were most likely young students. $85 \%$ of the participants were students and $79 \%$ of the participants were at the age between 19 and 24 . Although students and young generation may provide good representation of general e-book users, it is suggested to diversify the age and 


\section{Issues in Information Systems}

Volume 15, Issue II, pp. 1-7, 2014

occupation of the participants for future studies. In addition, the e-book contents provided in the experiment were in travel category. Future studies may broaden the coverage of the contents to generalize the results.

\section{REFERENCES}

1. Cooper, D. R. and C. W. Emory (1995). Business Research Method, Chicago: Richard D. Irwin.

2. Csıkszentmihályi, M. (1978). Beyond boredom and anxiety: Experiencing flow in work and play. 2nd ED, San Francisco: Jossey Bass.

3. Csıkszentmihályi, M. (1990). Flow: The Psychology of Optimal Experience. New York: Harper and Row.

4. Hair, J. F., Black, B., Babin, B., Anderson, R. E., \& Tatham, R. L. (2006). Multivariate Data Analysis, 6th ED, Pearson Prentice Hall.

5. Lu, Y., Zhou, T., \& Wang, B. (2009). Exploring Chinese users' acceptance of instant messaging using the theory of planned behavior, the technology acceptance model, and the flow theory. Computers in Human Behavior, 25(1), 29, 39.

6. Rogers, E. M. (1995). Diffusion of innovation. New York: Free Press.

7. Jung, J., Chan, Olmsted, S., Park, B., \& Kim, Y. (2011). Factors affecting e-book reader awareness, interest, and intention to use. New Media \& Society, 14(2) 204, 224.

8. Shin, D. H. (2011). Understanding e-book users: Uses and gratification expectancy model. New Media \& Society, 13(2), 260, 278.

9. Wiersma, W. (2000). Research methods in education: An introduction, 7th ED. Boston: Allyn and Bacon 